\title{
Nanotechnology: a promising method for oral cancer detection and diagnosis
}

\author{
Xiao-Jie Chen ${ }^{1}$, Xue-Qiong Zhang ${ }^{2 *}$, Qi Liu ${ }^{3}$, Jing Zhang ${ }^{1,4}$ and Gang Zhou ${ }^{1,4^{*}}$
}

\begin{abstract}
Oral cancer is a common and aggressive cancer with high morbidity, mortality, and recurrence rate globally. Early detection is of utmost importance for cancer prevention and disease management. Currently, tissue biopsy remains the gold standard for oral cancer diagnosis, but it is invasive, which may cause patient discomfort. The application of traditional noninvasive methods-such as vital staining, exfoliative cytology, and molecular imaging-is limited by insufficient sensitivity and specificity. Thus, there is an urgent need for exploring noninvasive, highly sensitive, and specific diagnostic techniques. Nano detection systems are known as new emerging noninvasive strategies that bring the detection sensitivity of biomarkers to nano-scale. Moreover, compared to current imaging contrast agents, nanoparticles are more biocompatible, easier to synthesize, and able to target specific surface molecules. Nanoparticles generate localized surface plasmon resonances at near-infrared wavelengths, providing higher image contrast and resolution. Therefore, using nano-based techniques can help clinicians to detect and better monitor diseases during different phases of oral malignancy. Here, we review the progress of nanotechnology-based methods in oral cancer detection and diagnosis.
\end{abstract}

Keywords: Oral cancer, Nanotechnology, Molecular imaging, Biomarker detection

\section{Background}

Cancer is a critical public health problem worldwide that has brought great burden to society. In 2016, an estimated 1,685,210 new cases and 595,690 cancer deaths occurred in the United States alone [1]. Oral cancer is the sixth most common cancer globally and has a 5-year survival rate of around 50\% [2]. According to US cancer statistics, approximately 31,910 new cases of oral cancer and 6490 oral cancer deaths occurred in 2016 [3]. Oral cancer is an aggressive cancer that mainly affects oral epithelial cells, may develop metastasis, and even results in death [4]. The major type of malignancy is oral squamous cell carcinomas (OSCC), which accounts for more than $90 \%$ of all oral cancers [5]. These tumors may invade the mucosa of the tongue, buccal, floor of mouth, alveolar and the hard palate, and the tongue is reported to be

\footnotetext{
*Correspondence: zhangxq@whut.edu.cn; zhougang@whu.edu.cn

${ }^{2}$ School of Chemistry, Chemical Engineering and Life Sciences, Wuhan

University of Technology, Wuhan 430070, People's Republic of China

${ }^{4}$ Department of Oral Medicine, School and Hospital of Stomatology,

Wuhan University, Wuhan 430079, People's Republic of China

Full list of author information is available at the end of the article
}

the most common subsite, with poor prognosis $[1,6]$. Oral carcinogenesis is often due to long-term exposure to various potential risk factors, which may lead to accumulation of multiple genetic mutations [4]. Several major risk factors for oral cancer, including smoking, alcohol consumption, and human papillomavirus infection, with smoking acting as the leading cause of cancer death [3, 7]. Besides, habitual use of the areca nut is another risk factor that closely associated with oral cancer, especially in Indian subcontinent [8].

The formation of oral cancer is a multifactorial and multistep process [6]. Oral leukoplakia, oral erythroplakia, oral lichen planus, oral submucous fibrosis, actinic keratosis, and discoid lupus erythematosus are common oral potentially malignant disorders (OPMD) that are known to have the potential for malignant transformation $[8,9]$. Thus, early detection of OPMD and oral cancer is critical for the prognosis of diseases [5]. To date, scalpel biopsy and histopathological examinations are still the standard diagnostic procedures applied to ascertain the oral potentially malignant and malignant lesions $[17,18]$. However, the biopsy procedure is often invasive, 
which may cause patients anxiety and discomfort [10]. The selection of resection margins depends largely on the histopathological assessments, and the results can be affected by the quality of the specimens and pathologists' subjective judgments $[11,12]$. In addition, the assessments are unable to detect small numbers of genetically abnormal cells at the margins, thus leaving the risk of recurrence $[13,14]$.

In the past few decades, a variety of pain-free diagnostic strategies have been developed. Non-invasive visual tools such as toluidine blue (TB) staining, autofluorescence (VELscope) and chemiluminescence (ViziLite) have been used solely or in combination as adjuvant tests to detect potentially malignant lesions [15-19]. In oral epithelial dysplasia cases, the sensitivity and specificity of TB, VELscope and ViziLite are reported to be $84.1 \%$ and $15.3,77.3$ and $27.8,56.8$ and $65.8 \%$, respectively [15]. Exfoliated cells, serum, and saliva are the most commonly used non-invasive samples for oral cancer detection since they are easily accessible, convenient, and cost-effective [11, 20]. For oral cancer diagnosis, the sensitivity and specificity of exfoliative cytology is reported to be 93.5 and $50.6 \%$, respectively [21]. The biomarker with high sensitivity and specificity in serum is combined detection of Cyclin D1 and epidermal growth factor receptor (EGFR), while the reliable marker in saliva is CD44 [22, 23]. Imaging techniques are used as diagnostic adjuncts to the histopathological assessments since they are noninvasive and done in real-time [24]. Radiographic imaging modalities-including magnetic resonance imaging (MRI), computed tomography (CT), cone beam computed tomography (CBCT), and positron emission tomography (PET)-are commonly used for clinical establishment of oral cancer stages and treatment plans [24, 25]. Raman spectroscopy, elastic scattering spectroscopy, diffuse reflectance spectroscopy, narrow-band imaging, and confocal reflectance microscopy are common optical diagnostic methods that distinguish malignant lesions from normal oral mucosa by reflecting changes within tissues through returned optical signals [11, 26-32].

However, these noninvasive methods still have some limitations [12]. The visual tools are highly subjective and depend on the expertise of the investigators [16-18]. The main deficiency of exfoliative cytology technology, which is based on the quantitative cytomorphometry and DNA aneuploidy, is the low detection specificity, resulting from the collection of disaggregated cells [12, 33, 34]. Moreover, the sensitivity for traditional detection methods is limited as the biomarkers with low concentrations in the tissue samples or body fluids may not be detected [35]. Although the imaging methods have provided real-time cancer cell morphology, their sensitivity for detecting small, earlier intraepithelial lesions are insufficient [36].
Thus, novel detection methods need to be explored to bring clinical benefits, including (1) accurately predicting the malignant risk of OPMDs, (2) specifically detecting oral cancer based on molecular targeting, (3) providing ultrasensitive detection strategies at nano-scale, (4) making real-time suggestions for the extent of surgical resection margins, and (5) monitoring oral cancer prognosis in a convenient way after treatment.

According to the US National Nanotechnology Initiative, nanotechnology refers to the manipulation of matter with the length scale of $1-100 \mathrm{~nm}$ in at least one dimension $[37,38]$. In the past few decades, nanotechnologies have been applied in various fields, especially in the medical field [39]. One of the most hotly researched subfield of nanotechnology is nanomedicine, which increases the possibility of specific targeted cancer therapy [40]. Moreover, nanotechnology is also a useful tool for cancer detection, and monitoring the disease as it metastasizes [41-44]. To date, nanotechnology has been applied in the detection and diagnosis of various cancers, such as cervical cancer, lung cancer, breast cancer, gastric cancer, nasopharyngeal cancer, and oral cancer [45-52]. As far as we know, the application of nano-based detection methods for oral cancer has not been systematically reviewed. In this review, we highlighted the various nanotechnologies that have been developed for oral cancer detection and diagnosis. The application of nanotechnology for in vitro and in vivo bioimaging of oral cancer was shown in Fig. 1.

\section{Nanotechnology-based detection and diagnostic methods \\ Nano-based molecular imaging \\ Magnetic resonance imaging}

Magnetic resonance imaging (MRI) is reported to be suitable for the assessment of the primary tumor and bone invasion, as well as the outlining of the actual tumor borders during surgery $[25,53]$. Commonly used positive MRI contrast agents-Gd3+ complexed with diethyltriamine-pentaacetic acid (Gd-DTPA) or tetra azacyclododecane-1,4,7,10-tetraacetic acid (Gd-DOTA)-can shorten tissue longitudinal relaxation times (T1) [54]. However, the contrast agents distribute throughout the entire body after being intravenously injected, but do not specifically accumulate in tumors. In addition, the blood circulation life time for Gd-DTPA or Gd-DOTA is very short, approximately only $1-1.5 \mathrm{~h}$ [55]. The contrast agents usually consist of superparamagnetic nanoparticles with coating layers [56].

With the advancement in nanotechnology, various types of nanoparticles have been applied as specific MRI contrast agents for cancer screening [54]. Nano-contrast agents have the ability to recognize unique cell surface 


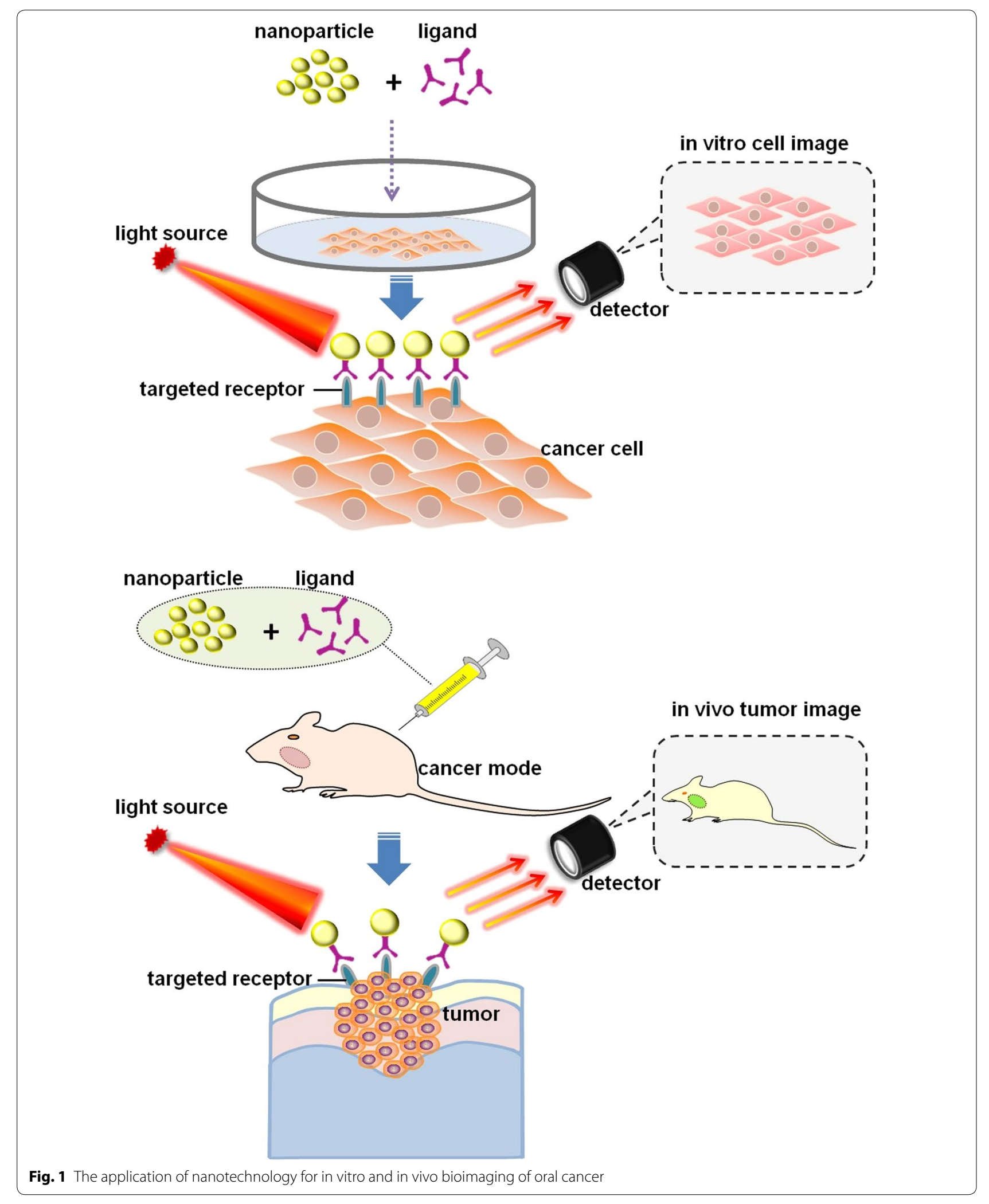


markers and prolonged blood circulation half-life, exhibiting better MRI contrast properties [57]. The most commonly studied superparamagnetic iron oxide (SPIO) and ultrasmall superparamagnetic iron oxide (USPIOs) nanoparticles, which can shorten T2 and T2*, have already been used as negative contrast agents for detecting liver and spleen diseases [58].

Nano-contrast agents have also been studied in oral cancers. For example, Asifkhan et al. combined the folate preconjugated chitosan and magnetic poly (lactide-coglycolide) (PLGA) nanoparticles to create an MRI contrast agent (Fig. 2) [59]. The overall T2 relaxation time was shortened, and the nanoparticle relaxivity was enhanced thereby providing better imaging contrast [59]. Meanwhile, the folate receptor positive KB oral cancer cells showed increased nanoparticle uptake and caused significant enhancement in cytotoxicity [59]. This nano agent not only provided high contrast cancer imaging but also simultaneously provided cancer therapy. Another novel magnetic nano-contrast agent was developed based on Gd3+ doped amorphous $\mathrm{TiO}_{2}$ and was suitable for $\mathrm{T} 1$ weighted MRI [60]. The size of this agent was reported to be about $25 \mathrm{~nm}$, which is much smaller than SPIO $(50 \mathrm{~nm})$ [58]. The potential of inducing hemolysis, platelet aggregation, and plasma coagulation was studied, and no adverse reaction was reported [60]. As a consequent, the folic acid conjugated nanoparticles were specifically aggregated on the surface of folate receptor positive oral cancer KB cells, leaving normal L929 cells unstained [60]. Notably, this nano-contrast agent showed enhanced longitudinal relaxivity, magnetic resonance, and excellent biocompatibility for MRI.

\section{Optical coherence tomography}

Optical coherence tomography (OCT) is a direct simulation of ultrasound. It produces cross-sectional architectural images of subsurface tissues, such as epithelial layers and basement membranes, using infrared light with a penetration depth of about $2 \mathrm{~mm}$, and is suitable for early oral cancer detection and oral dysplasia monitoring [61]. The resolution of OCT is reported to be around $10 \mu \mathrm{m}$ which is higher than that of other noninvasive diagnostic techniques, such as CT, MRI, and ultrasound [50,62]. Although OCT is a non-invasive and real-time clinical diagnostic method for cell and stromal morphology imaging, the contrast remains insufficient, especially between neoplastic and normal tissues [63].

Gold nanoparticles are promising OCT contrast agents. They are biocompatible, easy to synthesize, and can provide localized surface plasmon resonances at near-infrared wavelengths that avoid predominant absorption in tissues [64]. For example, the EGFR monoclonal antibodies conjugated $\mathrm{Au}$ nanoparticles with a diameter of $71 \mathrm{~nm}$ have been applied to enhance the contrast of OCT images of oral dysplasia in a hamster model [65]. Meanwhile, microneedles and ultrasound were utilized to overcome the obstacle for Au NP delivery. This multimodal delivery was demonstrated to be effective in improving OCT penetration depth and resulted in an approximately $150 \%$ increased contrast level in oral carcinogenesis [65].

\section{Photoacoustic imaging}

Photoacoustic imaging is a new emerging optical diagnostic technology. By using a short laser pulse, it

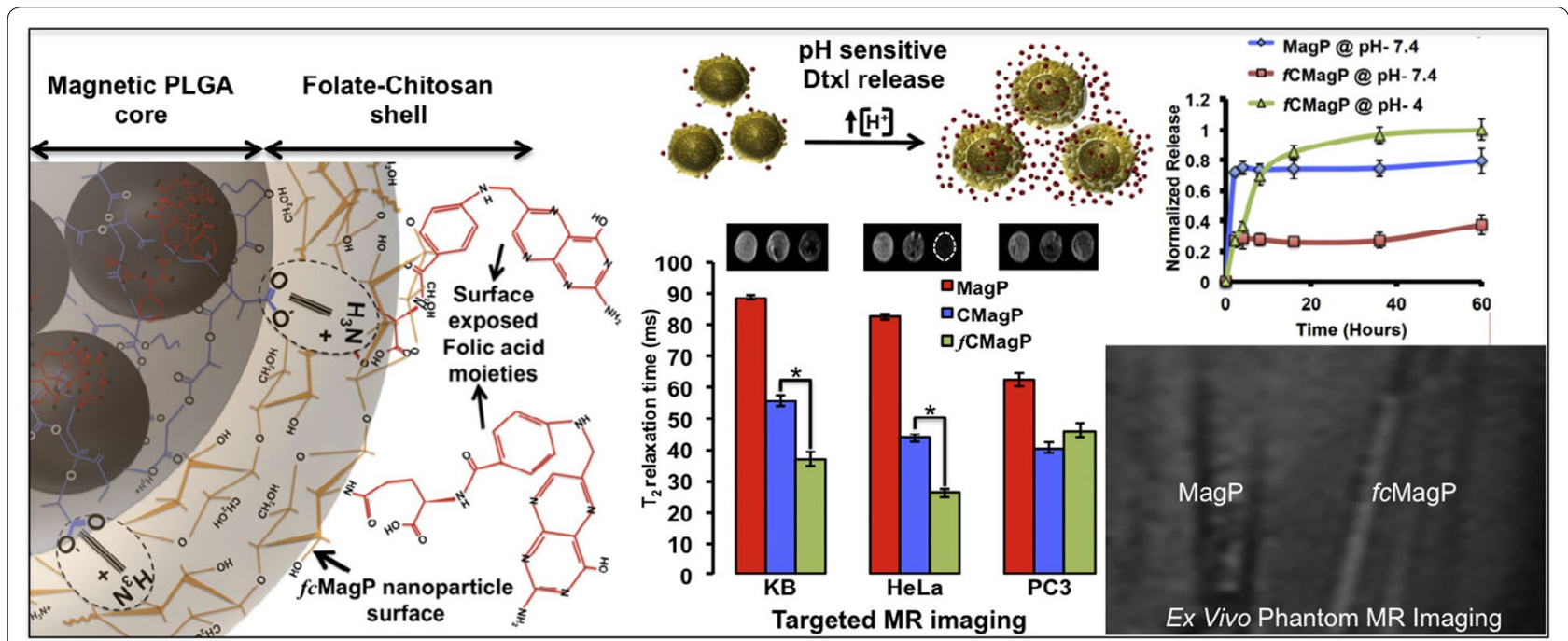

Fig. 2 Representation of the magnetic core-shell hybrid nanoparticles for receptor targeted MRI (Reprinted with permission from [59]. Copyright 2017 Journal of Colloid and Interface Science) 
generates ultrasound transients from tissues, thereby causing transient thermoelastic expansions after optical absorption [66-68]. These photoacoustic waves are being then transformed into photoacoustic images according to their arrival times after collected by an ultrasound transducer $[69,70]$. The ultrasound provides high spatial resolution for structural phenotyping and is a useful tool for assessing lymph nodes following a radical surgery $[71,72]$. Consequently, the optical contrast can be significantly improved while maintaining the high spatial resolution of ultrasound [73]. Compared to conventional optical imaging, photoacoustic imaging has improved imaging depth, about $6 \mathrm{~cm}$ [69]. Though various exogenous contrast agents-such as methylene blue, ICG, and GNs-have been used to enhance the photoacoustic imaging contrast, the gold nanoparticles are considered a more attractive contrast agent due to their ability to conjugate biomolecules and their production of stronger photoacoustic imaging signals $[67,69,74]$. To date, photoacoustic imaging has demonstrated great potential in brain, breast, and prostate cancer diagnosis $[67,73,75,76]$.

Luke et al. introduced ultrasound-guided spectroscopic photoacoustic imaging technology for detecting lymph node micrometastases in a metastatic murine model of OSCC (Fig. 3) [77]. Using anti-EGFR antibody conjugated molecularly activated plasmonic nanosensors (MAPS), the study showed that the MAPS shifted their absorption spectrum to the near-infrared region [77]. In addition, large ultrasound-guided spectroscopic photoacoustic signals appeared in micrometastases as small as $50 \mathrm{~mm}$ within $30 \mathrm{~min}$ after MAPS injection [77]. These findings offer an alternate to sentinel lymph node biopsy analysis of oral cancer resection.
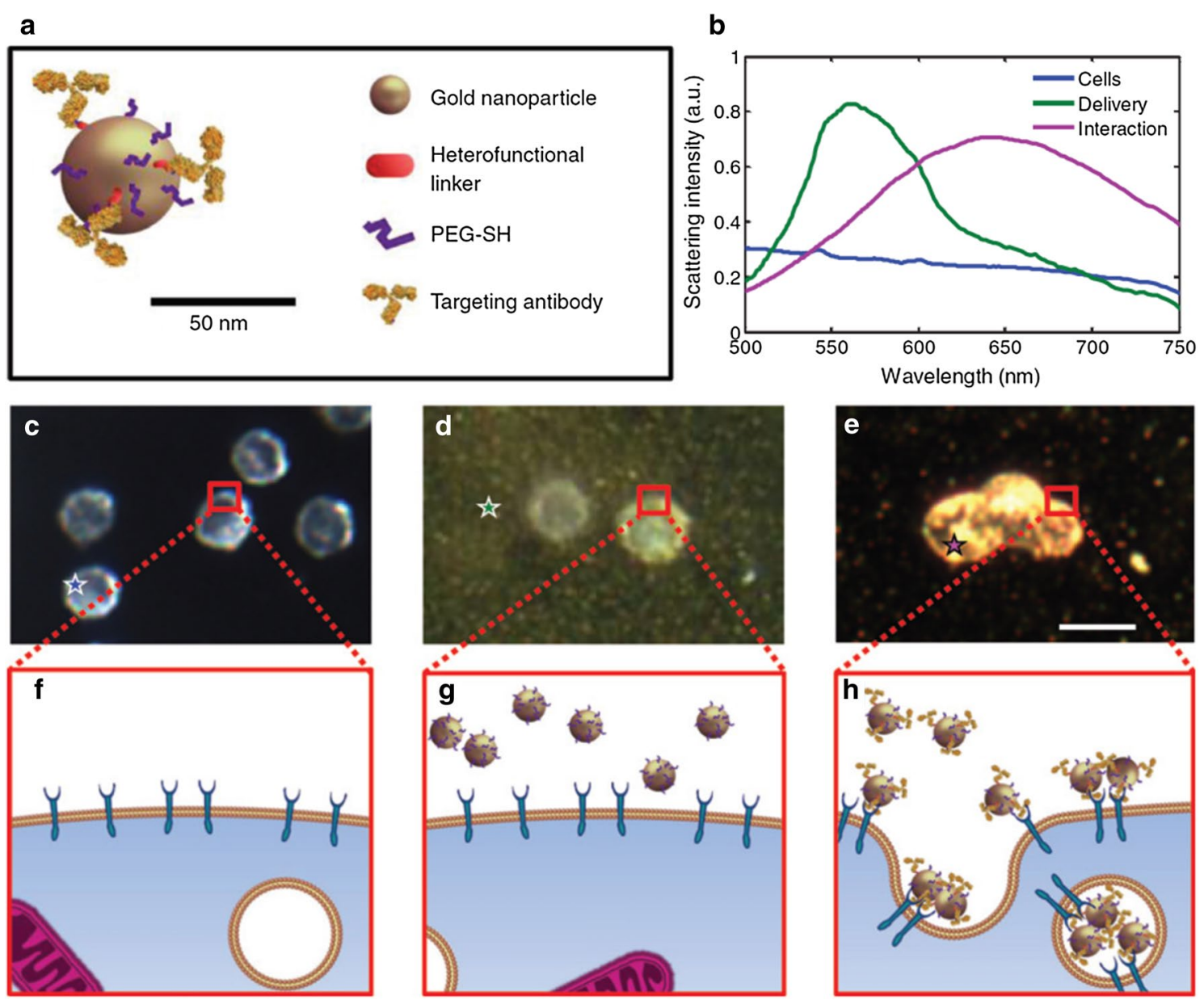

Fig. 3 Representation of the photoacoustic imaging using anti-EGFR antibody conjugated molecularly activated MAPS. a A schematic of the EGFR-targeted MAPS; b optical spectra obtained hyperspectral dark-field microscopy; $\mathbf{c}, \mathbf{f}$ cancer cells in the absence of gold nanoparticles; $\mathbf{d}$, $\mathbf{g}$ cells in the presence of nonspecific AuNPs; e, h cells labeled with MAPS (Reprinted with permission from [77]. Copyright 2014 Cancer Research) 


\section{Surface plasmon resonance scattering}

Surface plasmon waves are formed by collective oscillation of conduction electrons in noble metals [78]. Recently, gold nanoparticles have been commonly applied for surface plasmon resonance scattering since they can resonantly scatter visible and near-infrared light due to their surface plasmon oscillation [78]. In addition, they are easy to prepare, readily bioconjugated, and have low cytotoxicity, making them suitable for biomolecular labeling and targeting [79]. It is reported that the conjugated nanoparticles tended to aggregate together, inducing a greatly enhanced surface plasmon resonance scattering compared to unconjugated nanoparticles [80].

El-Sayed et al. recorded surface plasmon resonance scattering images and surface plasmon resonance absorption spectra after cell incubation [81]. Light-scattering images showed that the EGFR conjugated nanoparticles bind specifically to the surface of the cancer cells with high concentration, while the binding to noncancerous cells was nonspecific and random [81]. Micro absorption spectra showed that the absorption maximum for conjugated nanoparticles was $545 \mathrm{~nm}$, without aggregation tendency, while unconjugated colloidal gold nanoparticles accumulated inside cells and aggregated with an absorption maximum around $552 \mathrm{~nm}$ [81]. As a result, the anti-EGFR antibody conjugated nanoparticles showed $600 \%$ greater affinity to malignant oral epithelial cell lines HOC 313 clone 8 and HSC 3 than to the nonmalignant cell line $\mathrm{HaCaT}$ [81]. In addition, the surface plasmon resonance property of gold nanoparticles was shown to have the ability to increase Raman scattering in saliva samples of oral cancer patients [63, 78]. High optical signals were produced by enhanced surface plasmon resonance when the gold nanoparticles gathered around the target cancerous cells, due to their conjugation with anti-EGFR [63]. The sensitivity was observed to be around $70 \%$ of the current technique, which needs to be further improved [63].

\section{Surface-enhanced Raman spectroscopy}

Raman spectroscopy is a vibrational spectroscopic technique based on inelastic interactions between light and matter [82]. The normal, premalignant, or malignant lesions are distinguished by inelastic scattering of light, which can be a laser in the visible, near-infrared, or near-ultraviolet range [83]. The signals in normal tissues are homogeneous but heterogeneous in malignant cells, reflecting the changes in chemical characterization and molecular structure of the lesions [84]. Raman spectroscopy is a near-field effect and has a low penetration depth. Its clinical application has been limited by the weak Raman signal intensity and the slow speed of spectrum acquisitions $[78,83]$.
Recently, nanoparticles have been applied as exogenous contrast agents, in order to acquire Raman signal with high speed and resolution [85-87]. After directly adsorbed on the nanoparticle surface, the molecules emit an amplified Raman scattering intensity, known as surface-enhanced Raman scattering (SERS) [83, 88]. A study introduced small, spherical, near-infrared region sensitive and SERS active gold nanoparticles with highly narrow intra-nanogap structures for single oral cancer cell HSC-3 imaging (Fig. 4) [89]. The gold nanoparticles can selectively target intracellular organelles and were specifically distributed in cytoplasm, mitochondria, and nuclei. Finally, high speed Raman imaging was achieved within $30 \mathrm{~s}$ with a high resolution of $50 \times 50$ pixels [89].

Nanospheres, nanorods, nanocubes, nanobranches, and nanobipyramids are different shapes of gold nanoparticles [90, 91]. Gold nanorods (GNRs) have received much attention for molecular imaging because of their advantage of higher index sensitivity over spherical and cubic gold nanoparticles, which means minor changes in the surrounding environment of GNRs can result in significant longitudinal surface plasmon resonance (LSPR) peak wavelength variation $[90,92]$. Since the index sensitivities and longitudinal plasmon wavelengths of nanorods increase with aspect ratios, the use of nanorods with large aspect ratios can provide near-infrared region plasmon wavelengths and high index sensitivity for optical techniques [90, 91].

Wang et al. conjugated GNRs with rose bengal (RB), a specific probe for oral cancer cell target, and monitored optical absorption in the near-infrared region [93]. The RB molecules have the ability to bind with the protein or nucleic acid of cancer cell lysate, whereafter the RB-GNR probes aggregated, inducing red-shift in the near-infrared absorption wavelength [93]. This RB-GNR platform provided a specific and quantitative method for oral cancer cell lysate analysis with a detection sensitivity of 2000 cells $/ \mathrm{ml}$ [93]. Liu et al. described a paper-based SERS technology in combination with exfoliative cytology for screening of exfoliated cells from oral cancer patients and healthy individuals [94]. Cells were placed on a plasmonic paper with GNRs adsorbed on it, and spectra were acquired afterward. Sensitivity and specificity were both $100 \%$ for distinguishing exfoliated cells from normal and cancer tissues, based on the $\mathrm{I}_{1600 / 1440}$ and $I_{1440 / 1340}$ peak ratios of the spectra values [94]. This paper-based SERS platform has overcome the drawbacks of traditional exfoliative cytology, such as low sensitivity and subjective cytologic interpretation [94].

\section{Diffusion reflection imaging}

In diffusion reflection imaging, a small portion of the white light entering the tissue is absorbed or transmitted, 


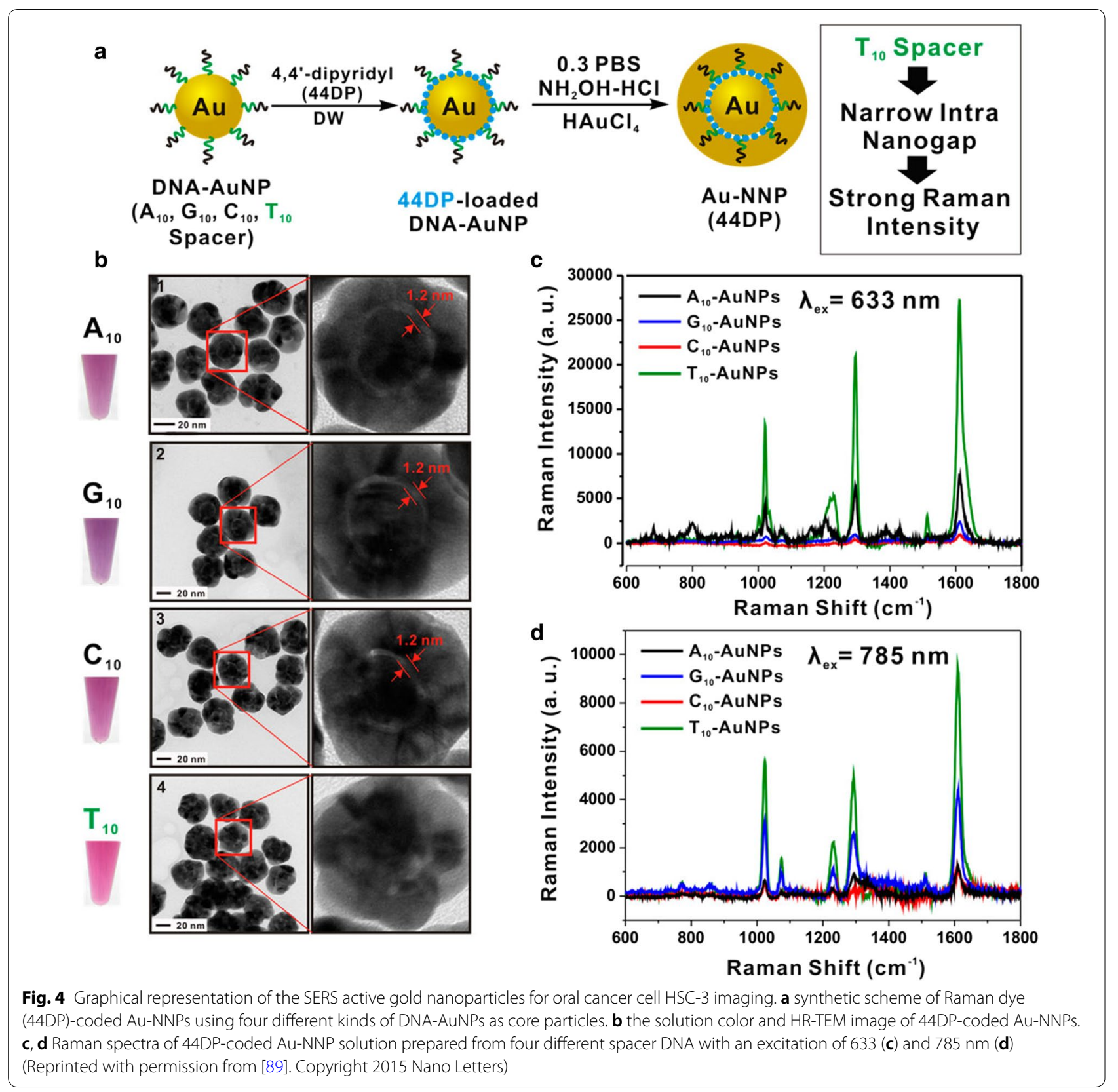

while the rest undergoes multiple elastic scattering and gets diffusely reflected [95]. The reflected light is greatly affected by cytologic and morphologic changes during epithelial tissue cancerization, including nuclear size, collagen content, extracellular matrix structure, epithelial thickness, and blood flow variation [28, 96]. It is reported that recording diffuse reflectance images can help to determine surgical margins and is a useful tool to differentiate normal mucosa, OPMD, and oral cancer [96-98].

In oral cancer, $14.3 \%$ of tumor margins after surgical excision were identified to have residual carcinoma [99]. Accurate determination of tumor margins is critical for complete surgical resection of residual diseases in oral cancer and may reduce the high rate of recurrence [100]. The accuracy of routine microscopic examination after frozen sections is limited by the $30.7-47.3 \%$ shrinkage of the frozen tissues [101]. Meanwhile, for the paraffinembedded tissue section, results are only available after the operation, making the intraoperative identification challenging [101]. Thus, efforts should be made to achieve a real-time and high sensitive way for more complete tumor resections.

Ankri et al. conjugated GNRs to monoclonal antibodies against EGFR and evaluated the margins of human 
OSCC specimens by diffusion reflection imaging [102]. Air scanning electron microscopy was used to visualize the nanorods in tissues, showing the GNRs-EGFR spread a distance of $1 \mathrm{~mm}$ between the tumor and the healthy regions. Diffusion reflection imaging was then performed in a resolution of $1 \mathrm{~mm}$, suggesting that the tumor edge is in the region of $4-5 \mathrm{~mm}$, which is consistent with the commonly used cutoff of $5 \mathrm{~mm}$ for a close margin [100]. This study group has also tested diffusion reflection imaging of GNRs-EGFR on a mice OSCC model induced by 4-nitroquinoline- $N$-oxide [103]. GNRs specifically attached to areas histologically identified as OSCC, with high reflectance at $780 \mathrm{~nm}$ over 17 intensity units. The overall specificity and sensitivity was 97 and $87 \%$, respectively [103]. Moreover, the reflectance spectrum at $780 \mathrm{~nm}$ was found to be moderate in areas of carcinoma in situ, but absent in normal epithelium. The optical properties showed significant changes-more than $80 \%$ of the invasive cancer and more than $30 \%$ of carcinoma in situ [103]. The group has also found that this modality is suitable for discriminating benign from malignant oral lesions since the reflectance intensity increased as the dysplastic changes increased [104]. Thus, the group has demonstrated that diffusion reflection imaging is a promising technique for the screening of malignant oral lesions and detecting residual disease during operation.

\section{Quantum dots imaging}

Quantum dots are nanometer-sized semiconductor crystals that luminesce through quantum confinement effects $[105,106]$. Quantum dots have several advantages that could overcome the limitations of conventional fluorescent dyes, such as size-tunable emission, wide excitation spectra, strong luminescence and excellent stability against photobleaching [106-108]. In addition, changing the size and composition of quantum dots allows for obtaining a wide range of spectrum, from ultraviolet to the near infrared $[109,110]$.

Currently, quantum dots have been applied in the molecular and cell imaging of OSCC both in vitro and in vivo. It has been demonstrated that quantum dots have high fluorescence intensity, low nonspecific binding, and good stability against photobleaching for the in vitro imaging of human oral cancer cells Tca8113, SCC-25 and BcaCD885 [111-114]. Most of the quantum dots used for in vivo imaging were linked to molecules with the ability to target cancer cells [115]. Recently, it was reported that the near-infrared quantum dots with an emission wavelengths range of 700-900 $\mathrm{nm}$ have strong tissue penetration and are not harmful in vivo [114, 115]. Meanwhile, quantum dots with emission wavelengths between 400 and $600 \mathrm{~nm}$ are able to avoid the interference of tissue autofluorescence, making them suitable for bioimaging
$[116,117]$. Studies have proven that quantum dots with an emission wavelength of $800 \mathrm{~nm}$ conjugated with EGFR monoclonal antibodies or arginine-glycine-aspartic acid sequence can generate high quality images of OSCC (Fig. 5) [117-119]. The technique also offers great potential in personalized therapy for OSCC [117-119].

\section{Nano-based ultrasensitive biomarker detection}

Currently, plenty of novel proteomic, genomic, and transcriptomic biomarkers are being researched. Exploration of tumor molecular biomarkers-such as tumor necrosis factor-alpha (TNF- $\alpha$ ), vascular endothelial growth factor (VEGF), EGFR, and interleukin 6 (IL 6)-holds great promise for early cancer detection and diagnosis [22, 120, 121]. Routine measurement methods-including enzyme-linked immunosorbent assay (ELISA), immunohistochemistry, Western Blot, and polymerase chain reaction-still bear a limited detection sensitivity ranging from $\mathrm{pM}$ to $\mathrm{fM}\left(10^{-12}\right.$ to $\left.10^{-15} \mathrm{M}\right)$ concentration levels $[22,23,35]$. The application of nanotechnology may enhance the detection sensitivity for biomarkers with low concentrations in the tissue samples or body fluids [122, 123].

The saliva peptide finger print technique is a useful tool for salivary proteomics analysis and can predict potential biomarkers valuable for cancer diagnosis [124]. A study utilized matrix-assisted laser-desorption ionization-timeof-flight mass spectrometry (MALDI-TOF-MS) for analyzing the expression spectrum of salivary peptides in 40 OSCC patients and 23 normal controls [125]. Nanomaterial-based magnetic beads were used for selective enrichment of low-molecular-mass peptides. It is noteworthy that 50 proteins expression levels were significantly different between OSCC patients and healthy controls. As a result, the mass peaks of 1285.6 and $1432.2 \mathrm{Da}$, which were both identified as histatin-3, were correlated with OSCC progression. This study introduced a novel highthroughput, non-invasive strategy for valuable oral cancer biomarkers screening [125]. The specific advantages of magnetic beads constructed on nanomaterial over other types of separation beads have not yet been illustrated.

A nano-based single biomarker detection method has also been utilized for oral cancer detection. A study detected TNF- $\alpha$ by gold protein chip method using a total internal reflection fluorescence microscopy (TIRFM) [35]. A $4 \times 5$ nanoarray incorporating $500 \mathrm{~nm}$ diameter gold spots was achieved on $10 \mathrm{~mm}$ square glass substrates. The TNF- $\alpha$ detection sensitivity was reported to be at the attomolar (aM) concentration level $\left(\times 10^{-18}\right)$, enabling ultra-sensitive oral cancer detection [35]. However, this method could not be used for precise quantitative analysis. Another 


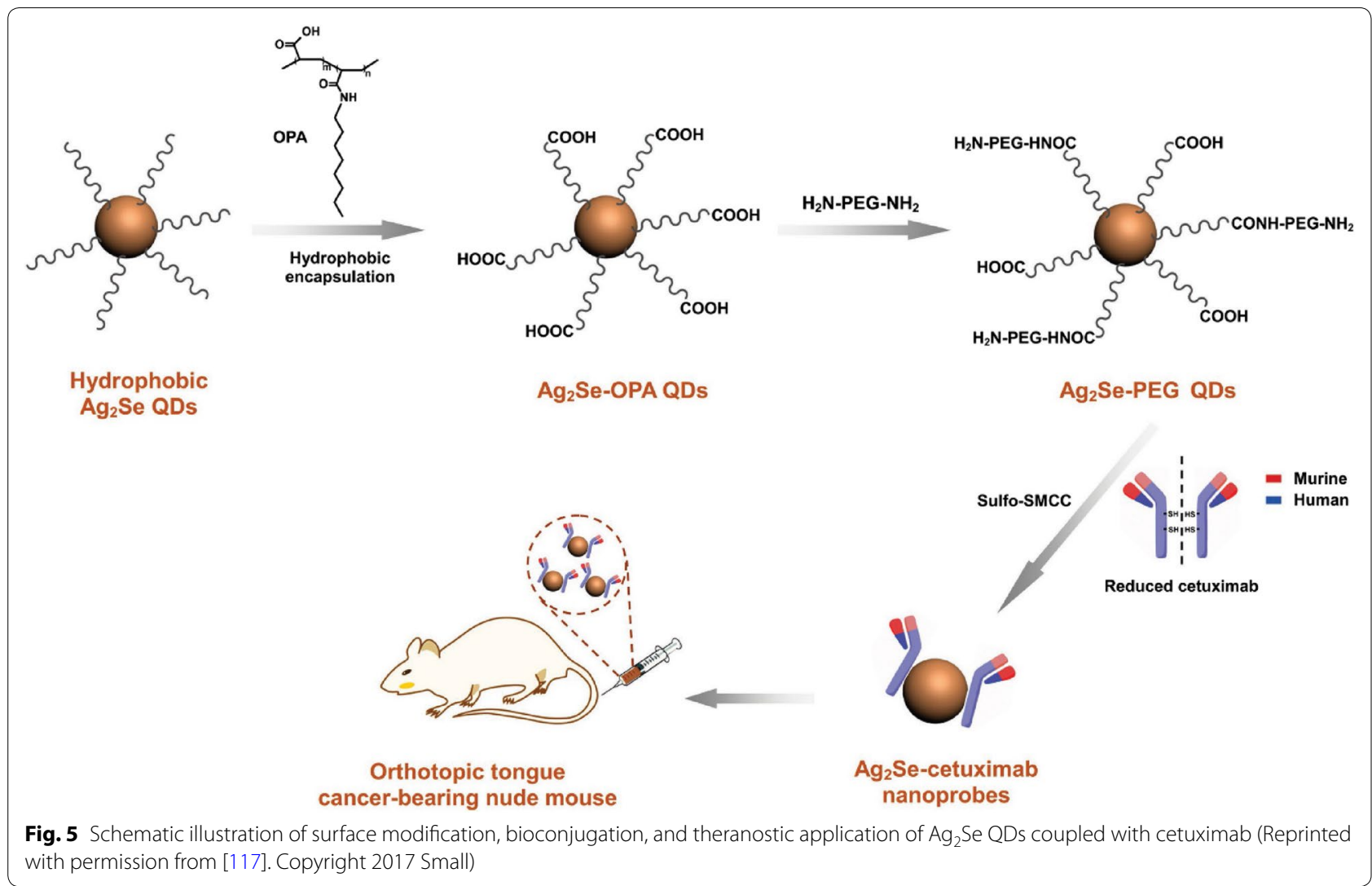

study described the analysis of oral cancer bio marker EGFR with exfoliative cytology specimens of 41 OPMD or OSCC patients and 11 healthy volunteers, using a nano-bio-chip sensor technique [126]. A total of 51 measurement parameters were collected, and biochemical and morphologic changes were further analyzed. The EGFR expression level-along with nuclear area, nuclear diameter, and nuclear-to-cytoplasmic ratiowas significantly altered in oral lesions with diagnosed squamous cell carcinoma or dysplasia [126]. Using ultra-sensitive atomic force microscopy (AFM) and field emission scanning electron microscopy (FESEM) with high resolution $(\sim 1 \mathrm{~nm})$, another study exhibited the substructure of single human saliva exosomes and interpreted the nanoscale structures of exosomes under varying forces, revealing reversible mechanical deformation [127]. Further, cell-type specific marker CD63 was detected by using $10 \mathrm{~nm}$ gold beads on individual exosomes. The nanoscale biomechanical, morphological, and surface biomolecular properties of saliva exosomes are found to be critical for the oral cancer diagnosis [127]. Although these two systems have made it possible for the quantitative analysis of cellular biomarkers, the systems described above can only be used for single biomarker analysis.
It is well-known that single oral cancer biomarkers cannot provide reliable diagnoses [128]. Multiplexed biomarker detection can minimize false positives and negatives arising from single biomarker analysis [128]. A multiplexed biomarker detection approach measured a four-protein panel of biomarkers using an ultrasensitive electrochemical microfluidic array [129]. The microfluidic device contained an array of nanostructured sensors, and plenty of magnetic beads were labeled. The four-protein panel-including interleukin-6, interleukin-8, VEGF, and VEGF-C-was analyzed in 78 oral cancer patient serum samples and 49 controls, and showed a clinical diagnostic sensitivity and specificity for 89 and $98 \%$, respectively [129]. The study provided a lowcost, easily fabricated method for accurate clinical oral cancer diagnosis. Another study analyzed proteins biomarkers in conditioned media of oral squamous cell lines HN12, HN13, OSCC-3 and CAL27 by utilizing a nano ultra-performance liquid chromatography (nanoUPLC) ion-mobility mass spectrometry [130]. A total of approximately 952 proteins-including known cancer biomarker proteins IL-6, IL-8, VEGF-A, and VEGF-C were identified. This nano-UPLC-Q-TOF assay provided a high-throughput approach to quantify proteins and compare protein expression levels across different samples, 


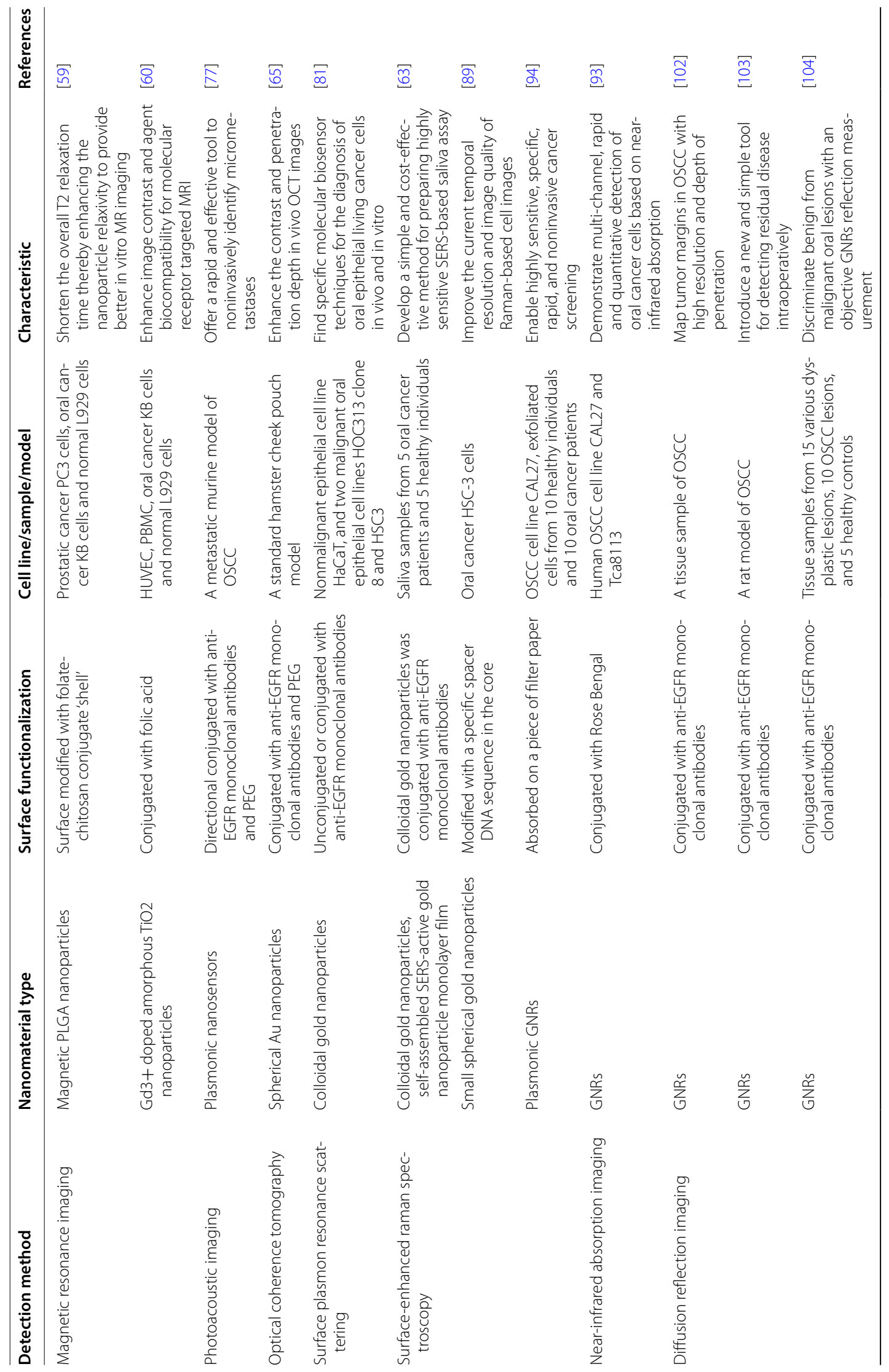




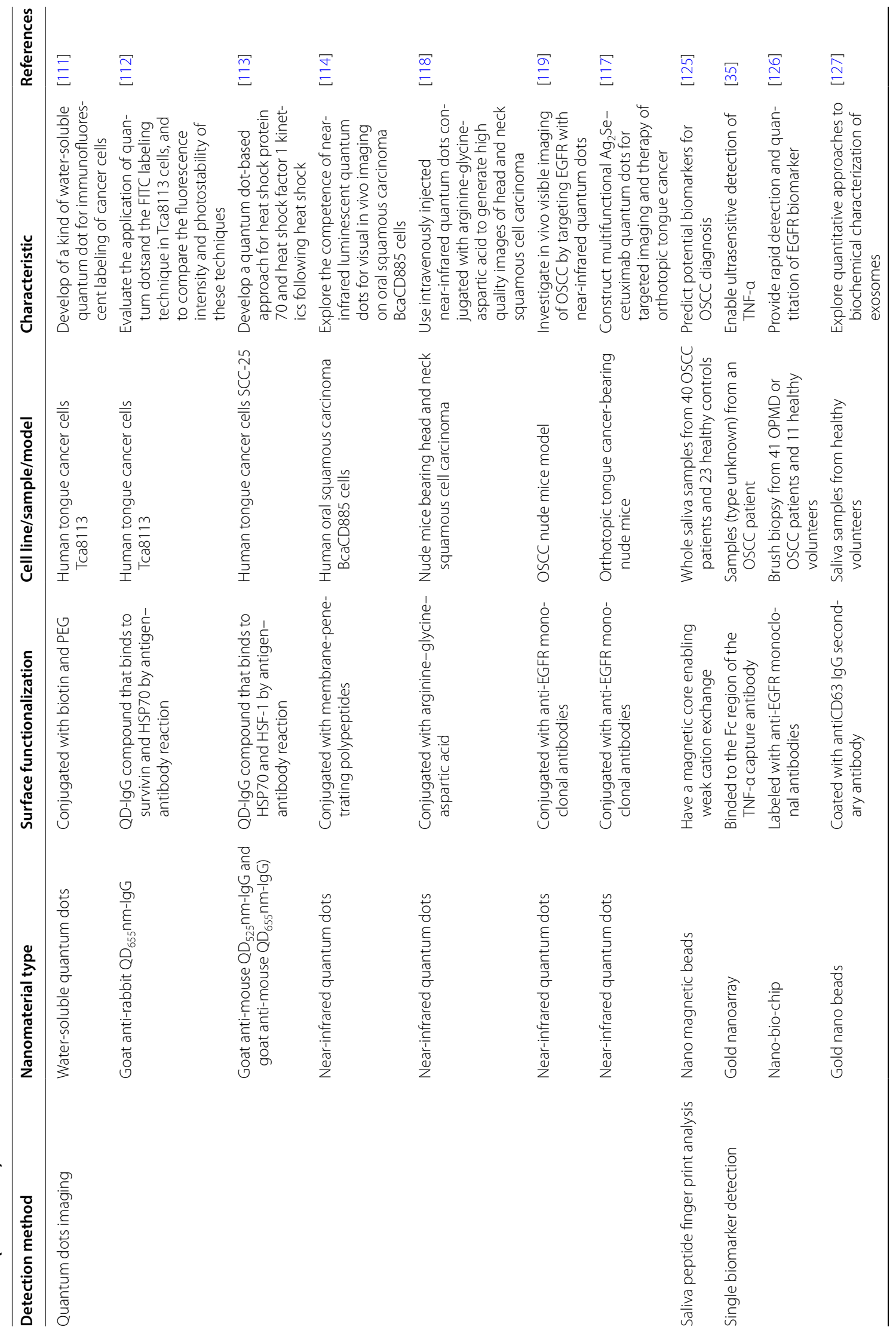




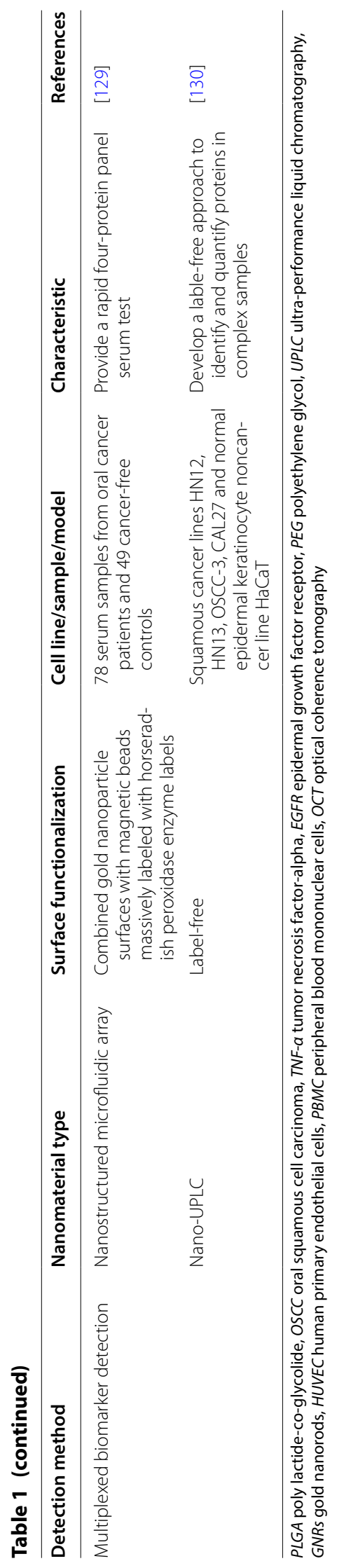




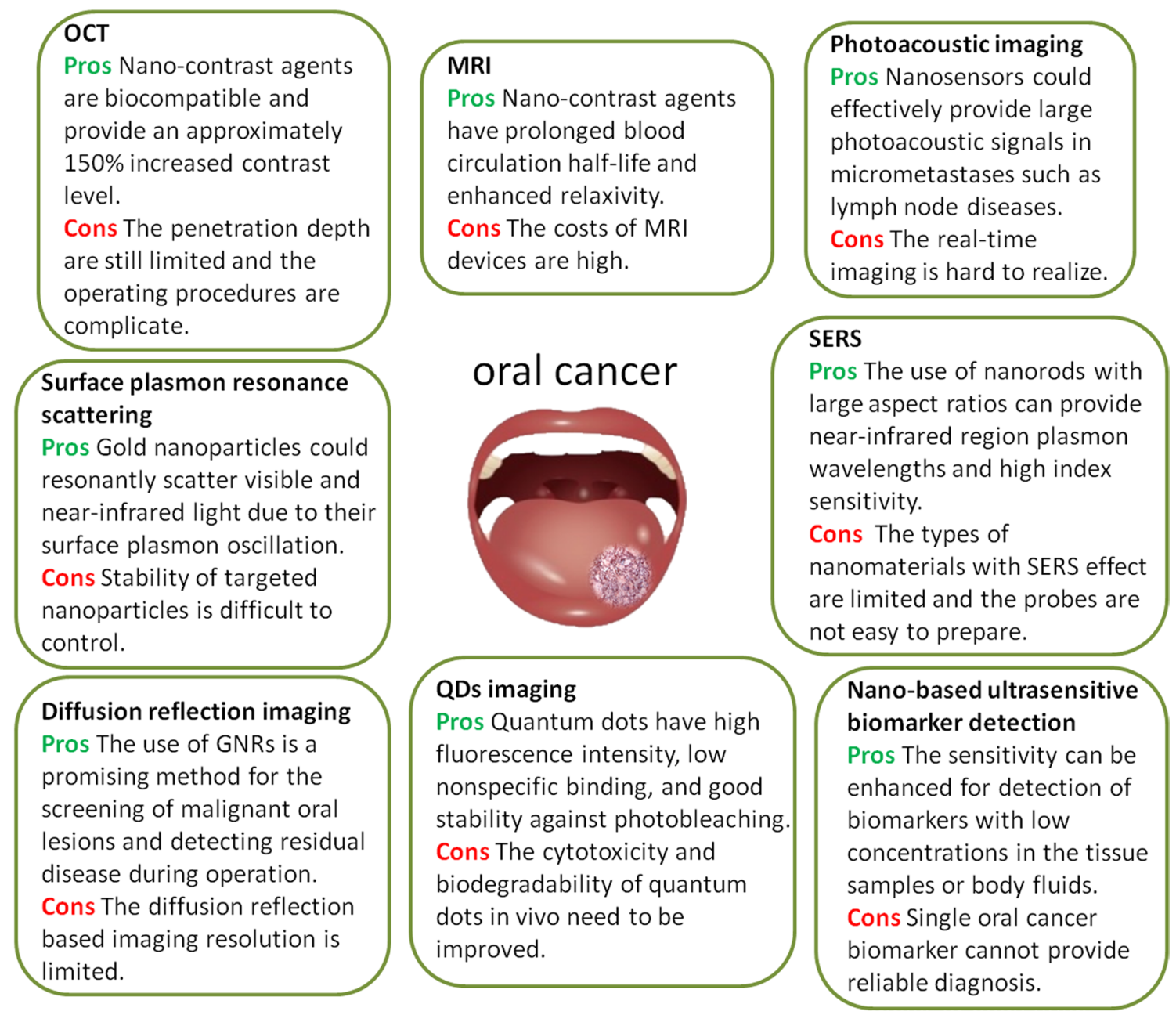

Fig. 6 The pros and cons of different nanotechnology for bioimaging and biomarker detection of oral cancer

without the need for stable isotope labeling. The identification of peptides was unlimited with the fragmentation technique [130].

\section{Conclusion and perspective}

Ranking as one of the top 10 cancers worldwide, oral cancer has a poor prognosis and a high recurrence rate, and the time and accuracy of diagnosis directly affects disease outcomes [131]. In the past few decades, nanotechnology has brought new techniques to cancer diagnosis [36, 38, 132, 133]. The performance parameters of nanoparticles-such as biocompatibility, function-specific size and shape, blood circulation half-life, and targeting to specific cell surface molecules-can be controlled by modulating their fabrication materials, methods or surface chemistry, making nanoparticles a promising diagnostic material [79]. The present review article has critically introduced nano-based detection strategies for oral cancers, and summarized various kinds of nanomaterials, sample types, and the characteristic of each technique in Table 1. The pros and cons of each nanotechnology for bioimaging and molecular detection of oral cancer were shown in Fig. 6. In the oral cavity, the use of nanoparticles has not only achieved noninvasive real-time diagnosis with high sensitivity and specificity but also assisted with accurately identifying surgical margins, indicating the potential to reduce the reliance on tissue biopsy and histopathological assessment in many cases.

Nano-based contrast agents for MRI, OCT and photoacoustic imaging have lower toxicity, prolonged blood circulation half-life, and the ability to target unique cell surface molecules. Compared to routine contrast agents, nano agents exhibit better image contrast properties and improved penetration depth. In optical imaging, nanoparticles enable sufficient signals and sub-cellular spatial resolution. They can generate surface plasmon resonance at near-infrared wavelengths, gathered around 
the targeted cell surface, and the optical resonance properties of nanorods can be regulated over a broad range by adjusting their sizes and shapes. Quantum dots with size-tunable emission, wide excitation spectrum, high intensity of luminescence, and excellent photochemical stability have overcome the disadvantages of traditional fluorescence markers. As for cancer biomarker detection, nano-based materials-such as nano beads, gold nanoarray, and nano-bio-chips-offer high throughput screening for potential biomarkers and have brought the level of detection sensitivity to the nanoscale. Therefore, the small and earlier intraepithelial lesions missed by common techniques can potentially be detected by nanotechnologies, making oral diseases more readily cured.

Nano-based diagnostic methods act as a promising tool to provide real-time, convenient, and cost-effective diagnosis for oral cancer detection and diagnosis. They can provide molecular targeted imaging, analyze biomarkers at nano-scale, enable intraoperative identification of surgical resection margins, and monitor oral cancer prognosis after treatment. Although these technologies have been studied in ex vivo studies of tissue and saliva samples and in vivo studies in animal models, further efforts should be employed before these strategies can be successfully applied in clinical diagnosis.

\begin{abstract}
Abbreviations
OPMD: oral potentially malignant disorders; OSCC: oral squamous cell carcinomas; TB: toluidine blue; EGFR: epidermal growth factor receptor; MRI: magnetic resonance imaging; CT: computed tomography; CBCT: cone beam computed tomography; PET: positron emission tomography; Gd-DTPA: Gd3 + complexed with diethyltriamine-pentaacetic acid; Gd-DOTA: tetra azacyclododecane1,4,7,10-tetraacetic acid; SPIO: superparamagnetic iron oxide; USPIO: ultrasmall superparamagnetic iron oxide; MAPS: molecularly activated plasmonic nanosensors; SERS: surface-enhanced Raman scattering; GNRs: gold nanorods; LSPR: longitudinal surface plasmon resonance; RB: rose bengal; TNF-a: tumor necrosis factor-alpha; VEGF: vascular endothelial growth factor; IL 6: interleukin 6; ELISA: en-zyme-linked immunosorbent assay; MALDI-TOF-MS: matrixassisted laser-desorption ionization-time-of-flight mass spectrometry; TIRFM: total internal reflection fluorescence microscopy; AFM: atomic force microscopy; FESEM: field emission scanning electron microscopy; PEG: polyethylene glycol; UPLC: ultra-performance liquid chromatography; PLGA: poly lactide-coglycolide; HUVEC: human primary endothelial cells; PBMC: peripheral blood mononuclear cells.
\end{abstract}

\section{Authors' contributions}

XJC designed the review and drafted the manuscript. XQZ, QL, JZ and GZ helped with the manuscript editing. GZ reviewed the manuscript drafts. All authors read and approved the final manuscript.

\footnotetext{
Author details

${ }^{1}$ The State Key Laboratory Breeding Base of Basic Science of Stomatology (Hubei-MOST) and Key Laboratory of Oral Biomedicine Ministry of Education School and Hospital of Stomatology, Wuhan University, Wuhan 430079, People's Republic of China. ${ }^{2}$ School of Chemistry, Chemical Engineering and Life Sciences, Wuhan University of Technology, Wuhan 430070, People's Republic of China. ${ }^{3}$ Division of Pharmacoengineering and Molecular Pharmaceutics and Center for Nanotechnology in Drug Delivery, Eshelman School of Pharmacy, University of North Carolina at Chapel Hill, Chapel Hill, NC 27599, USA. ${ }^{4}$ Department of Oral Medicine, School and Hospital of Stomatology, Wuhan University, Wuhan 430079, People's Republic of China.
}

\section{Acknowledgements}

This work was supported by Grants from National Natural Science Foundation of China (No. 81771080, No. 81371147) to Professor Zhou Gang.

\section{Competing interests}

The authors declare that they have no competing interests.

Availability of data and materials

Not applicable.

\section{Consent for publication \\ Not applicable.}

Ethics approval and consent to participate

Not applicable.

\section{Funding}

Not applicable.

\section{Publisher's Note}

Springer Nature remains neutral with regard to jurisdictional claims in published maps and institutional affiliations.

Received: 6 March 2018 Accepted: 1 June 2018

Published online: 11 June 2018

References

1. Siegel RL, Miller KD, Jemal A. Cancer statistics, 2016. CA Cancer J Clin. 2016;66:7-30.

2. Calixto G, Bernegossi J, Fonseca-Santos B, Chorilli M. Nanotechnologybased drug delivery systems for treatment of oral cancer: a review. Int J Nanomed. 2014;9:3719-35.

3. Torre LA, Bray F, Siegel RL, Ferlay J, Lortet-Tieulent J, Jemal A. Global cancer statistics, 2012. CA Cancer J Clin. 2015;65:87-108.

4. Tanaka T, Ishigamori R. Understanding carcinogenesis for fighting oral cancer. J Oncol. 2011;2011:603740.

5. Warnakulasuriya S. Global epidemiology of oral and oropharyngeal cancer. Oral Oncol. 2009;45:309-16.

6. Ng JH, lyer NG, Tan MH, Edgren G. Changing epidemiology of oral squamous cell carcinoma of the tongue: a global study. Head Neck. 2017;39:297-304.

7. Jemal A, Bray F, Center MM, Ferlay J, Ward E, Forman D. Global cancer statistics. CA Cancer J Clin. 2011;61:69-90.

8. Arakeri G, Patil SG, Aljabab AS, Lin KC, Merkx MAW, Gao S, et al. Oral submucous fibrosis: an update on pathophysiology of malignant transformation. J Oral Pathol Med. 2017;46:413-7.

9. Khan Z, Khan S, Christianson L, Rehman S, Ekwunife O, SamkangeZeeb F. Smokeless tobacco and oral potentially malignant disorders in south asia: a systematic review and meta-analysis. Nicotine Tob Res. 2017;20:12-21.

10. Benergossi J, Calixto G, Fonseca-Santos B, Aida KL, de Cassia Negrini T, Duque $C$, et al. Highlights in peptide nanoparticle carriers intended to oral diseases. Curr Top Med Chem. 2015;15:345-55.

11. Liu D, Zhao X, Zeng X, Dan H, Chen Q. Non-invasive techniques for detection and diagnosis of oral potentially malignant disorders. Tohoku J Exp Med. 2016;238:165-77.

12. Mercadante V, Paderni C, Campisi G. Novel non-invasive adjunctive techniques for early oral cancer diagnosis and oral lesions examination. Curr Pharm Des. 2012;18:5442-51.

13. Wikner J, Grobe A, Pantel K, Riethdorf S. Squamous cell carcinoma of the oral cavity and circulating tumour cells. World J Clin Oncol. 2014:5:114-24.

14. Brennan JA, Mao L, Hruban RH, Boyle JO, Eby YJ, Koch WM, et al. Molecular assessment of histopathological staging in squamous-cell carcinoma of the head and neck. N Engl J Med. 1995;332:429-35.

15. Awan KH, Morgan PR, Warnakulasuriya S. Assessing the accuracy of autofluorescence, chemiluminescence and toluidine blue as diagnostic 
tools for oral potentially malignant disorders - a clinicopathological evaluation. Clin Oral Investig. 2015;19:2267-72.

16. Chainani-Wu N, Madden E, Cox D, Sroussi H, Epstein J, Silverman S Jr. Toluidine blue aids in detection of dysplasia and carcinoma in suspicious oral lesions. Oral Dis. 2015;21:879-85.

17. Balasubramaniam AM, Sriraman R, Sindhuja P, Mohideen K, Parameswar RA, Muhamed Haris KT. Autofluorescence based diagnostic techniques for oral cancer. J Pharm Bioallied Sci. 2015;7:S374-7.

18. Kammerer PW, Rahimi-Nedjat RK, Ziebart T, Bemsch A, Walter C, AlNawas $B$, et al. A chemiluminescent light system in combination with toluidine blue to assess suspicious oral lesions-clinical evaluation and review of the literature. Clin Oral Investig. 2015;19:459-66.

19. Giovannacci I, Vescovi P, Manfredi M, Meleti M. Non-invasive visual tools for diagnosis of oral cancer and dysplasia: a systematic review. Med Oral Patol Oral Cir Bucal. 2016;21:e305-15.

20. Ye X, Zhang J, Tan Y, Chen G, Zhou G. Meta-analysis of two computerassisted screening methods for diagnosing oral precancer and cancer. Oral Oncol. 2015;51:966-75.

21. Sekine J, Nakatani E, Hideshima K, Iwahashi T, Sasaki H. Diagnostic accuracy of oral cancer cytology in a pilot study. Diagn Pathol. 2017;12:27.

22. Fernandez-Olavarria A, Mosquera-Perez R, Diaz-Sanchez RM, SerreraFigallo MA, Gutierrez-Perez JL, Torres-Lagares D. The role of serum biomarkers in the diagnosis and prognosis of oral cancer: a systematic review. J Clin Exp Dent. 2016;8:e184-93.

23. Sannam Khan R, Khurshid Z, Akhbar S, Faraz Moin S. Advances of salivary proteomics in oral squamous cell carcinoma (OSCC) detection: an update. Proteomes. 2016:4:E41.

24. Keshavarzi M, Darijani M, Momeni F, Moradi P, Ebrahimnejad H, Masoudifar A, et al. Molecular imaging and oral cancer diagnosis and therapy. J Cell Biochem. 2017;118:3055-60.

25. Sarrion Perez MG, Bagan JV, Jimenez Y, Margaix M, Marzal C. Utility of imaging techniques in the diagnosis of oral cancer. J Craniomaxillofac Surg. 2015:43:1880-94.

26. Mian SA, Yorucu C, Ullah MS, Rehman IU, Colley HE. Raman spectroscopy can discriminate between normal, dysplastic and cancerous oral mucosa: a tissue-engineering approach. J Tissue Eng Regen Med. 2016;11:3253-62.

27. Green B, Cobb AR, Brennan PA, Hopper C. Optical diagnostic techniques for use in lesions of the head and neck: review of the latest developments. Br J Oral Maxillofac Surg. 2014;52:675-80.

28. Stephen MM, Jayanthi JL, Unni NG, Kolady PE, Beena VT, Jeemon P, et al. Diagnostic accuracy of diffuse reflectance imaging for early detection of pre-malignant and malignant changes in the oral cavity: a feasibility study. BMC Cancer. 2013;13:278.

29. Piazza C, Del Bon F, Paderno A, Grazioli P, Perotti P, Barbieri D, et al. The diagnostic value of narrow band imaging in different oral and oropharyngeal subsites. Eur Arch Otorhinolaryngol. 2016;273:3347-53.

30. Lucchese A, Gentile E, Romano A, Maio C, Laino L, Serpico R. The potential role of in vivo reflectance confocal microscopy for evaluating oral cavity lesions: a systematic review. J Oral Pathol Med. 2016;45:723-9.

31. Gentile E, Maio C, Romano A, Laino L, Lucchese A. The potential role of in vivo optical coherence tomography for evaluating oral soft tissue: a systematic review. J Oral Pathol Med. 2017:46:864-76.

32. Sokolov K, Aaron J, Hsu B, Nida D, Gillenwater A, Follen M, et al. Optical systems for in vivo molecular imaging of cancer. Technol Cancer Res Treat. 2003;2:491-504

33. Omar E. Future imaging alternatives: the clinical non-invasive modalities in diagnosis of oral squamous cell carcinoma (OSCC). Open Dent J. 2015;9:311-8.

34. Liu Y, LiY, Fu Y, Liu T, Liu X, Zhang X, et al. Quantitative prediction of oral cancer risk in patients with oral leukoplakia. Oncotarget. 2017;118(10):3055-60.

35. Lee K, Lee S, Yu H, Kang SH. Ultra-sensitive detection of tumor necrosis factor-alpha on gold nano-patterned protein chip formed via E-beam nanolithography by total internal reflection fluorescence microscopy. J Nanosci Nanotechnol. 2010;10:3228-31.

36. Sharma P, Brown S, Walter G, Santra S, Moudgil B. Nanoparticles for bioimaging. Adv Colloid Interface Sci. 2006;123-126:471-85.

37. Ogle OE, Byles N. Nanotechnology in dentistry today. West Indian Med J. 2014;63:344-8.
38. Jaishree V, Gupta PD. Nanotechnology: a revolution in cancer diagnosis. Indian J Clin Biochem. 2012;27:214-20.

39. Ho D, Wang CH, Chow EK. Nanodiamonds: the intersection of nanotechnology, drug development, and personalized medicine. Sci Adv. 2015:1:e1500439.

40. Wang ZQ, Liu K, Huo ZJ, Li XC, Wang M, Liu P, et al. A cell-targeted chemotherapeutic nanomedicine strategy for oral squamous cell carcinoma therapy. J Nanobiotechnol. 2015;13:63.

41. Gharat SA, Momin M, Bhavsar C. Oral squamous cell carcinoma: current treatment strategies and nanotechnology-based approaches for prevention and therapy. Crit Rev Ther Drug Carrier Syst. 2016;33:363-400.

42. Bao C, Conde J, Curtin J, Artzi N, Tian F, Cui D. Bioresponsive antisense DNA gold nanobeacons as a hybrid in vivo theranostics platform for the inhibition of cancer cells and metastasis. Sci Rep. 2015;5:12297.

43. Han Y, An Y, Jia G, Wang X, He C, Ding Y, et al. Theranostic micelles based on upconversion nanoparticles for dual-modality imaging and photodynamic therapy in hepatocellular carcinoma. Nanoscale. 2018:10:6511-23.

44. Halo TL, McMahon KM, Angeloni NL, Xu Y, Wang W, Chinen AB, et al. NanoFlares for the detection, isolation, and culture of live tumor cells from human blood. Proc Natl Acad Sci USA. 2014;111:17104-9.

45. Zdobnova TA, Lebedenko EN, Deyev Scapital Em C. Quantum dots for molecular diagnostics of tumors. Acta Nat. 2011;3:29-47.

46. Jaiswal JK, Mattoussi H, Mauro JM, Simon SM. Long-term multiple color imaging of live cells using quantum dot bioconjugates. Nat Biotechnol. 2003;21:47-51.

47. Lee MH, Lee DH, Jung SW, Lee KN, Park YS, Seong WK. Measurements of serum C-reactive protein levels in patients with gastric cancer and quantification using silicon nanowire arrays. Nanomedicine. 2010;6:78-83

48. Adarsh N, Ramya AN, Maiti KK, Ramaiah D. Unveiling NIR aza-borondipyrromethene (BODIPY) dyes as Raman probes: surface-enhanced raman scattering (SERS)-guided selective detection and imaging of human cancer cells. Chemistry. 2017;23:14286-91.

49. Gonda K, Watanabe M, Tada H, Miyashita M, Takahashi-Aoyama Y, Kamei T, et al. Quantitative diagnostic imaging of cancer tissues by using phosphor-integrated dots with ultra-high brightness. Sci Rep. 2017:7:7509.

50. Pande P, Shrestha S, Park J, Gimenez-Conti I, Brandon J, Applegate $\mathrm{BE}$, et al. Automated analysis of multimodal fluorescence lifetime imaging and optical coherence tomography data for the diagnosis of oral cancer in the hamster cheek pouch model. Biomed Opt Express. 2016;7:2000-15.

51. Jackson AW, Chandrasekharan P, Ramasamy B, Goggi J, Chuang KH, $\mathrm{He} \mathrm{T}$, et al. Octreotide functionalized nano-contrast agent for targeted magnetic resonance imaging. Biomacromol. 2016;17:3902-10.

52. Kwon OS, Song HS, Conde J, Kim HI, Artzi N, Kim JH. Dual-color emissive upconversion nanocapsules for differential cancer bioimaging in vivo. ACS Nano. 2016;10:1512-21.

53. Hinni ML, Zarka MA, Hoxworth JM. Margin mapping in transoral surgery for head and neck cancer. Laryngoscope. 2013;123:1190-8.

54. Cheng W, Ping Y, Zhang Y, Chuang KH, Liu Y. Magnetic resonance imaging (MRI) contrast agents for tumor diagnosis. J Healthc Eng. 2013;4:23-45

55. Bennett KM, Jo J, Cabral H, Bakalova R, Aoki I. MR imaging techniques for nano-pathophysiology and theranostics. Adv Drug Deliv Rev. 2014;74:75-94.

56. Villaraza AJ, Bumb A, Brechbiel MW. Macromolecules, dendrimers, and nanomaterials in magnetic resonance imaging: the interplay between size, function, and pharmacokinetics. Chem Rev. 2010;110:2921-59.

57. Aryal S, Key J, Stigliano C, Landis MD, Lee DY, Decuzzi P. Positron emitting magnetic nanoconstructs for PET/MR imaging. Small. 2014;10:2688-96.

58. Brigger I, Dubernet C, Couvreur P. Nanoparticles in cancer therapy and diagnosis. Adv Drug Deliv Rev. 2002;54:631-51.

59. Shanavas A, Sasidharan S, Bahadur D, Srivastava R. Magnetic core-shell hybrid nanoparticles for receptor targeted anti-cancer therapy and magnetic resonance imaging. J Colloid Interface Sci. 2017;486:112-20.

60. Chandran P, Sasidharan A, Ashokan A, Menon D, Nair S, Koyakutty M. Highly biocompatible $\mathrm{TiO}(2): G d(3)(+)$ nano-contrast agent 
with enhanced longitudinal relaxivity for targeted cancer imaging. Nanoscale. 2011;3:4150-61.

61. Green B, Tsiroyannis C, Brennan PA. Optical diagnostic systems for assessing head and neck lesions. Oral Dis. 2016;22:180-4.

62. Troutman TS, Barton JK, Romanowski M. Optical coherence tomography with plasmon resonant nanorods of gold. Opt Lett. 2007;32:1438-40.

63. Kah JC, Kho KW, Lee CG, James C, Sheppard R, Shen ZX, et al. Early diagnosis of oral cancer based on the surface plasmon resonance of gold nanoparticles. Int J Nanomed. 2007;2:785-98.

64. Oldenburg AL, Hansen MN, Zweifel DA, Wei A, Boppart SA. Plasmonresonant gold nanorods as low backscattering albedo contrast agents for optical coherence tomography. Opt Express. 2006;14:6724-38.

65. Kim CS, Wilder-Smith P, Ahn YC, Liaw LH, Chen Z, Kwon YJ. Enhanced detection of early-stage oral cancer in vivo by optical coherence tomography using multimodal delivery of gold nanoparticles. J Biomed Opt. 2009;14:034008.

66. Bayer CL, Wlodarczyk BJ, Finnell RH, Emelianov SY. Ultrasound-guided spectral photoacoustic imaging of hemoglobin oxygenation during development. Biomed Opt Express. 2017:8:757-63.

67. Zhang M, Kim HS, Jin T, Yi A, Moon WK. Ultrasound-guided photoacoustic imaging for the selective detection of EGFR-expressing breast cancer and lymph node metastases. Biomed Opt Express. 2016;7:1920-31.

68. Xu C, Chen F, Valdovinos HF, Jiang D, Goel S, Yu B, et al. Bacteria-like mesoporous silica-coated gold nanorods for positron emission tomography and photoacoustic imaging-guided chemo-photothermal combined therapy. Biomaterials. 2018;165:56-65.

69. Jiang Y, Pu K. Advanced photoacoustic imaging applications of nearinfrared absorbing organic nanoparticles. Small. 2017:13:1700710

70. Bao C, Conde J, Pan F, Li C, Zhang C, Tian F, et al. Gold nanoprisms as a hybrid in vivo cancer theranostic platform for in situ photoacoustic imaging, angiography, and localized hyperthermia. Nano Res. 2016;9:1043-56.

71. Palasz P, Adamski L, Gorska-Chrzastek M, Starzynska A, Studniarek M. Contemporary diagnostic imaging of oral squamous cell carcinoma-a review of literature. Pol J Radiol. 2017:82:193-202.

72. Bui NQ, Cho SW, Moorthy MS, Park SM, Piao Z, Nam SY, et al. In vivo photoacoustic monitoring using 700-nm region Raman source for targeting Prussian blue nanoparticles in mouse tumor model. Sci Rep. 2018:8:2000.

73. Weber J, Beard PC, Bohndiek SE. Contrast agents for molecular photoacoustic imaging. Nat Methods. 2016:13:639-50.

74. Liang S, Li C, Zhang C, Chen Y, Xu L, Bao C, et al. CD44v6 monoclonal antibody-conjugated gold nanostars for targeted photoacoustic imaging and plasmonic photothermal therapy of gastric cancer stem-like cells. Theranostics. 2015;5:970-84.

75. Fan Q, Cheng K, Yang Z, Zhang R, Yang M, Hu X, et al. Perylene-diimidebased nanoparticles as highly efficient photoacoustic agents for deep brain tumor imaging in living mice. Adv Mater. 2015:27:843-7.

76. Horiguchi A, Shinchi M, Nakamura A, Wada T, Ito K, Asano T, et al. Pilot study of prostate cancer angiogenesis imaging using a photoacoustic imaging system. Urology. 2017;108:212-9.

77. Luke GP, Myers JN, Emelianov SY, Sokolov KV. Sentinel lymph node biopsy revisited: ultrasound-guided photoacoustic detection of micrometastases using molecularly targeted plasmonic nanosensors. Cancer Res. 2014;74:5397-408.

78. Hou C, Galvan DD, Meng G, Yu Q. Long-range surface plasmon resonance and surface-enhanced Raman scattering on X-shaped gold plasmonic nanohole arrays. Phys Chem Chem Phys. 2017;1 1:24126-34.

79. Lee SH, Lee JB, Bae MS, Balikov DA, Hwang A, Boire TC, et al. Current progress in nanotechnology applications for diagnosis and treatment of kidney diseases. Adv Healthc Mater. 2015:4:2037-45.

80. Sokolov K, Follen M, Aaron J, Pavlova I, Malpica A, Lotan R, et al. Realtime vital optical imaging of precancer using anti-epidermal growth factor receptor antibodies conjugated to gold nanoparticles. Cancer Res. 2003:63:1999-2004.

81. El-Sayed IH, Huang X, El-Sayed MA. Surface plasmon resonance scattering and absorption of anti-EGFR antibody conjugated gold nanoparticles in cancer diagnostics: applications in oral cancer. Nano Lett. 2005:5:829-34.
82. Yan B, Li B, Wen Z, Luo X, Xue L, Li L. Label-free blood serum detection by using surface-enhanced Raman spectroscopy and support vector machine for the preoperative diagnosis of parotid gland tumors. BMC Cancer. 2015;15:650

83. Harmsen S, Wall MA, Huang RM, Kircher MF. Cancer imaging using surface-enhanced resonance Raman scattering nanoparticles. Nat Protoc. 2017:12:1400-14.

84. Guze K, Pawluk HC, Short M, Zeng H, Lorch J, Norris C, et al. Pilot study: Raman spectroscopy in differentiating premalignant and malignant oral lesions from normal mucosa and benign lesions in humans. Head Neck. 2015;37:511-7.

85. Galloway TA, Cabo-Fernandez L, Aldous IM, Braga F, Hardwick LJ. Shell isolated nanoparticles for enhanced Raman spectroscopy studies in lithium-oxygen cells. Faraday Discuss. 2017:205:469-90.

86. Wang YW, Reder NP, Kang S, Glaser AK, Yang Q, Wall MA, et al. Raman-encoded molecular imaging with topically applied SERS nanoparticles for intraoperative guidance of lumpectomy. Cancer Res. 2017:77:4506-16

87. Conde J, Bao C, Cui D, Baptista PV, Tian F. Antibody-drug gold nanoantennas with Raman spectroscopic fingerprints for in vivo tumour theranostics. J Control Release. 2014;183:87-93.

88. Liu R, Zhao J, Han G, Zhao T, Zhang R, Liu B, et al. Click-functionalized SERS nanoprobes with improved labeling efficiency and capability for cancer cell imaging. ACS Appl Mater Interfaces. 2017;9:38222-9.

89. Kang JW, So PTC, Dasari RR, Lim DK. High resolution live cell Raman imaging using subcellular organelle-targeting SERS-sensitive gold nanoparticles with highly narrow intra-nanogap. Nano Lett. 2015;15:1766-72.

90. Chen H, Kou X, Yang Z, Ni W, Wang J. Shape- and size-dependent refractive index sensitivity of gold nanoparticles. Langmuir. 2008;24:5233-7.

91. El-Sayed MA. Some interesting properties of metals confined in time and nanometer space of different shapes. Acc Chem Res. 2001:34:257-64.

92. Tian F, Conde J, Bao C, Chen Y, Curtin J, Cui D. Gold nanostars for efficient in vitro and in vivo real-time SERS detection and drug delivery via plasmonic-tunable Raman/FTIR imaging. Biomaterials. 2016;106:87-97.

93. Wang JH, Wang B, Liu Q, Li Q, Huang H, Song L, et al. Bimodal optical diagnostics of oral cancer based on rose bengal conjugated gold nanorod platform. Biomaterials. 2013;34:4274-83.

94. Liu Q, Wang J, Wang B, Li Z, Huang H, Li C, et al. Paper-based plasmonic platform for sensitive, noninvasive, and rapid cancer screening. Biosens Bioelectron. 2014:54:128-34.

95. Chen C, Florian K, Rajesh K, Max R, Christian K, Florian S, et al. Recovering the superficial microvascular pattern via diffuse reflection imaging: phantom validation. Biomed Eng Online. 2015;14:87.

96. Jayanthi JL, Nisha GU, Manju S, Philip EK, Jeemon P, Baiju KV, et al. Diffuse reflectance spectroscopy: diagnostic accuracy of a non-invasive screening technique for early detection of malignant changes in the oral cavity. BMJ Open. 2011;1:e000071.

97. Lalla Y, Matias M, Farah CS. Oral mucosal disease in an Australian urban Indigenous community using autofluorescence imaging and reflectance spectroscopy. Aust Dent J. 2015;60:216-24.

98. Miller DM, Jokerst NM. Flexible silicon sensors for diffuse reflectance spectroscopy of tissue. Biomed Opt Express. 2017;8:1512-24.

99. Varvares MA, Poti S, Kenyon B, Christopher K, Walker RJ. Surgical margins and primary site resection in achieving local control in oral cancer resections. Laryngoscope. 2015;125:2298-307.

100. Tasche KK, Buchakjian MR, Pagedar NA, Sperry SM. Definition of "Close Margin" in oral cancer surgery and association of margin distance with local recurrence rate. JAMA Otolaryngol Head Neck Surg. 2017;143:1166-72.

101. Abbas SA, Ikram M, Tariq MU, Raheem A, Saeed J. Accuracy of frozen sections in oral cancer resections, an experience of a tertiary care hospital. J Pak Med Assoc. 2017:67:806-9.

102. Ankri R, Ashkenazy A, Milstein Y, Brami Y, Olshinka A, Goldenberg-Cohen $\mathrm{N}$, et al. Gold nanorods based air scanning electron microscopy and diffusion reflection imaging for mapping tumor margins in squamous cell carcinoma. ACS Nano. 2016;10:2349-56.

103. Fixler D, Ankri R, Kaplan I, Novikov I, Hirshberg A. Diffusion reflection: a novel method for detection of oral cancer. J Dent Res. 2014;93:602-6. 
104. Hirshberg A, Allon I, Novikov I, Ankri R, Ashkenazy A, Fixler D. Gold nanorods reflectance discriminate benign from malignant oral lesions. Nanomedicine. 2017;13:1333-9.

105. Liu L, Miao Q, Liang G. Quantum dots as multifunctional materials for tumor imaging and therapy. Materials (Basel). 2013;6:483-99.

106. Bera D, Qian L, Tseng TK, Holloway PH. Quantum dots and their multimodal applications: a review. Materials. 2010;3:2260-345.

107. Rosenthal SJ, Chang JC, Kovtun O, MCBride JR, Tomlinson ID. Biocompatible quantum dots for biological applications. Chem Biol. 2011;18:10-24.

108. Bakalova R, Zhelev Z, Kokuryo D, Spasov L, Aoki I, Saga T. Chemical nature and structure of organic coating of quantum dots is crucial for their application in imaging diagnostics. Int J Nanomed. 2011;6:1719-32.

109. Michalet X, Pinaud FF, Bentolila LA, Tsay JM, Doose S, Li JJ, et al. Quantum dots for live cells, in vivo imaging, and diagnostics. Science. 2005;307:538-44.

110. Medintz IL, Uyeda HT, Goldman ER, Mattoussi H. Quantum dot bioconjugates for imaging, labelling and sensing. Nat Mater. 2005;4:435-46.

111. Li Z, Wang K, Tan W, Li J, Fu Z, Ma C, et al. Immunofluorescent labeling of cancer cells with quantum dots synthesized in aqueous solution. Anal Biochem. 2006;354:169-74.

112. Zhao JJ, Chen J, Wang ZP, Pan J, Huang YH. Double labeling and comparison of fluorescence intensity and photostability between quantum dots and FITC in oral tumors. Mol Med Rep. 2011;4:425-9.

113. Chen J, Pan J, Zhao J, Qiu X, Zheng J, Wang Z, et al. Quantum dot imaging for HSP70 and HSF1 kinetics in SCC25 cells with or without leucine deprivation following heat shock. Oncol Rep. 2013;29:2255-60.

114. Yang K, Cao YA, Shi C, Li ZG, Zhang FJ, Yang J, et al. Quantum dot-based visual in vivo imaging for oral squamous cell carcinoma in mice. Oral Oncol. 2010;46:864-8.

115. Yang K, Zhao C, Cao YA, Tang H, Bai YL, Huang H, et al. In vivo and in situ imaging of head and neck squamous cell carcinoma using nearinfrared fluorescent quantum dot probes conjugated with epidermal growth factor receptor monoclonal antibodies in mice. Oncol Rep. 2012;27:1925-31.

116. Aswathy RG, Yoshida Y, Maekawa T, Kumar DS. Near-infrared quantum dots for deep tissue imaging. Anal Bioanal Chem. 2010;397:1417-35.

117. Zhu CN, Chen G, Tian ZQ, Wang W, Zhong WQ, Li Z, et al. Near-infrared fluorescent Ag2Se-cetuximab nanoprobes for targeted imaging and therapy of cancer. Small. 2017;13:1602309.

118. Huang $\mathrm{H}$, Bai $\mathrm{YL}$, Yang $\mathrm{K}$, Tang $\mathrm{H}$, Wang $\mathrm{YW}$. Optical imaging of head and neck squamous cell carcinoma in vivo using arginine-glycine-aspartic acid peptide conjugated near-infrared quantum dots. Onco Targets Ther. 2013;6:1779-87.

119. Yang K, Zhang FJ, Tang H, Zhao C, Cao YA, Lv XQ, et al. In-vivo imaging of oral squamous cell carcinoma by EGFR monoclonal antibody conjugated near-infrared quantum dots in mice. Int J Nanomed. 2011;6:1739-45.

120. Saxena S, Sankhla B, Sundaragiri KS, Bhargava A. A review of salivary biomarker: a tool for early oral cancer diagnosis. Adv Biomed Res. 2017;6:90.

121. Almangush A, Heikkinen I, Makitie AA, Coletta RD, Laara E, Leivo I, et al. Prognostic biomarkers for oral tongue squamous cell carcinoma: a systematic review and meta-analysis. Br J Cancer. 2017;117:856-66.

122. Janissen $R$, Sahoo PK, Santos $C A$, da Silva AM, von Zuben AAG, Souto DEP, et al. InP nanowire biosensor with tailored biofunctionalization: ultrasensitive and highly selective disease biomarker detection. Nano Lett. 2017;17:5938-49.

123. Li X, Wei L, Pan L, Yi Z, Wang X, Ye Z, et al. Homogeneous immunosorbent assay based on single-particle enumeration using upconversion nanoparticles for the sensitive detection of cancer biomarkers. Anal Chem. 2018;90:4807-14.

124. Wei P, Kuo WP, Chen F, Hua H. Diagnostic model of saliva peptide finger print analysis of primary Sjogren's syndrome patients by using weak cation exchange magnetic beads. Biosci Rep. 2013;33:e00051.

125. Jiang WP, Wang Z, Xu LX, Peng X, Chen F. Diagnostic model of saliva peptide finger print analysis of oral squamous cell carcinoma patients using weak cation exchange magnetic beads. Biosci Rep. 2015;35:e00211.

126. Weigum SE, Floriano PN, Redding SW, Yeh CK, Westbrook SD, McGuff HS, et al. Nano-bio-chip sensor platform for examination of oral exfoliative cytology. Cancer Prev Res (Phila). 2010;3:518-28.

127. Sharma S, Rasool HI, Palanisamy V, Mathisen C, Schmidt M, Wong DT, et al. Structural-mechanical characterization of nanoparticle exosomes in human saliva, using correlative AFM, FESEM, and force spectroscopy. ACS Nano. 2010;4:1921-6.

128. Munge BS, Stracensky T, Gamez K, DiBiase D, Rusling JF. Multiplex immunosensor arrays for electrochemical detection of cancer biomarker proteins. Electroanalysis. 2016;28:2644-58.

129. Malhotra R, Patel V, Chikkaveeraiah BV, Munge BS, Cheong SC, Zain RB, et al. Ultrasensitive detection of cancer biomarkers in the clinic by use of a nanostructured microfluidic array. Anal Chem. 2012;84:6249-55.

130. Nassar AF, Williams BJ, Yaworksy DC, Patel V, Rusling JF. Rapid label-free profiling of oral cancer biomarker proteins using nano-UPLC-Q-TOF ion mobility mass spectrometry. Proteomics Clin Appl. 2016;10:280-9.

131. Ernani V, Saba NF. Oral cavity cancer: risk factors, pathology, and management. Oncology. 2015;89:187-95.

132. Conde J, Oliva N, Artzi N. Implantable hydrogel embedded dark-gold nanoswitch as a theranostic probe to sense and overcome cancer multidrug resistance. Proc Natl Acad Sci USA. 2015;112:E1278-87.

133. Prigodich AE, Randeria PS, Briley WE, Kim NJ, Daniel WL, Giljohann DA, et al. Multiplexed nanoflares: mRNA detection in live cells. Anal Chem. 2012;84:2062-6.

\footnotetext{
Ready to submit your research? Choose BMC and benefit from:

- fast, convenient online submission

- thorough peer review by experienced researchers in your field

- rapid publication on acceptance

- support for research data, including large and complex data types

- gold Open Access which fosters wider collaboration and increased citations

- maximum visibility for your research: over 100M website views per year
}

At $\mathrm{BMC}$, research is always in progress.

Learn more biomedcentral.com/submissions 